\title{
Monocytes and Polymorphonuclear Neutrophils of Patients with Streptococcal Pharyngitis Express Increased Numbers of Type I IgG Fc Receptors
}

\author{
Paul M. Guyre,* A. Scott Campbell,"\$ Wayne D. Kniffin, ${ }^{5}$ and Michael W. Fangert5 \\ Departments of ${ }^{*}$ Physiology, ${ }^{\ddagger}$ Microbiology, and ${ }^{\S}$ Medicine, Dartmouth Medical School, Hanover, New Hampshire 03756
}

\begin{abstract}
Studies using cultured cells have shown that gamma interferon (IFN- $\gamma$ ) induces the expression of FcrRI (the type I Fc receptor for IgG) on human polymorphonuclear neutrophils (PMN) and greatly increases the number of these receptors on human monocytes. Administration of rIFN- $\gamma$ in vivo also causes enhanced Fc $\gamma R I$ expression of these cell populations. Because streptococcal antigens are potent inducers of IFN- $\gamma$ in vitro, we postulated that IFN- $\gamma$ would be produced endogenously in vivo in patients with streptococcal infections. Such production of IFN- $\gamma$ in vivo, even at low levels, might be expected to induce the expression of Fc $\gamma$ RI on monocytes and neutrophils. To evaluate this possibility, we used monoclonal antibody 32 (mAb 32), which is specific for FcyRI, to quantitate the expression of this receptor on human peripheral blood cells. We measured the binding of mAb 32 to monocytes and PMNs isolated from healthy donors and from patients with group $A$ $\beta$-hemolytic streptococcal (GABHS) pharyngitis. PMNs from healthy donors $(n=12)$ had $700 \pm 600$ (mean \pm SD) mAb 32 binding sites. Patients with pharyngitis and negative throat culture for GABHS $(n=11)$ had $2,100 \pm 1,600$ sites on their PMNs. In contrast, the PMNs from patients with documented GABHS pharyngitis $(n=12)$ had $11,600 \pm 7,500 \mathrm{mAb} 32$ binding sites on their surface. There was a similar change in the expression of FcrRI on monocytes, with control monocytes having a mean of $19,900 \pm 3,200 \mathrm{mAb} 32$ binding sites per cell and the GABHS-positive monocytes having 47,500 $\pm 21,400$ sites. The GABHS-negative throat culture group had a slightly elevated number of FcrRI with a mean of $28,200 \pm 8,400$ sites. 10 patients with documented urinary tract infections and three patients with uncomplicated pyelonephritis had no elevation in FcrRI expression. These studies demonstrate that a localized group A streptococcal infection can cause systemic activation of the entire circulating pool of phagocytes, and suggest that a similar level of activation is uncommon in localized gram-negative infections of the urinary tract. (J. Clin Invest. 1990. 86:1892-1896.) Key words: Fc receptors $\bullet$ interferon activation - streptococcal infection
\end{abstract}

\section{Introduction}

Gamma interferon (IFN- $\gamma$ ), ${ }^{1}$ a lymphokine secreted by activated $\mathrm{T}$ lymphocytes, has been shown to be a major mediator

Address correspondence to Paul M. Guyre, Ph.D., Department of Physiology, Dartmouth Medical School, Hanover, NH 03756.

Received for publication 16 September 1988 and in revised form 12 June 1990.

1. Abbreviations used in this paper: $\mathrm{Fc} \gamma \mathrm{R}$, Fc portion of human immunoglobin G; GABHS, group A $\beta$-hemolytic streptococcal; IFN- $\gamma$, gamma interferon; PMN, polymorphonuclear neutrophil; rIFN- $\gamma$, recombinant IFN- $\gamma$.

\section{J. Clin. Invest.}

(C) The American Society for Clinical Investigation, Inc.

0021-9738/90/12/1892/05 \$2.00

Volume 86, December 1990, 1892-1896 of resistance to infectious agents, including $T$. gondii (1), $L$. monocytogenes (2), L. donovani (3), and $R$. conorii (4). IFN- $\gamma$ activates both murine and human mononuclear phagocytes, increasing oxidative metabolism $(5,6)$, antimicrobial activity $(7,8)$, and receptors for the Fc portion of human immunoglobulin $G(F c \gamma R)(9,10)$. Three Fc $\gamma R$ (Fc $\gamma R I$, II, and III) have been identified in association with human myeloid cells (reviewed by Unkeless et al., reference 11) and are recognized respectively by monoclonal antibodies 32 (12), IV.3 (13), and $3 G 8$ (14). Fc $\gamma$ RI has high affinity for human IgG1, is constitutively expressed on monocytes, and is induced to much higher expression in response to IFN- $\gamma$ (9). Moreover, we recently used mAb 32 to show that while polymorphonuclear neutrophils (PMNs) have $<3,000 \mathrm{Fc} \gamma \mathrm{RI}$ per cell, culture for $18 \mathrm{~h}$ with $40 \mathrm{U} / \mathrm{ml}$ of recombinant IFN- $\gamma$ results in the expression of 8,000-20,000 Fc $\gamma$ RI per PMN (15). Consistent with this effect of IFN- $\gamma$ on monocytes and PMNs in vitro, it has been demonstrated that parenteral administration of rIFN- $\gamma$ to patients causes increased expression of Fc $\gamma$ RI on circulating monocytes (16) and PMNs (Guyre P. M., and M. B. Garnick, unpublished observations) and also increases the capacity of monocytes to produce reactive oxygen intermediates (6).

Because streptococcal antigens are potent inducers of IFN- $\gamma$ production $(17,18)$, we postulated that Fc $\gamma$ RI levels would be elevated on monocytes and PMNs of patients who have streptococcal infections. We therefore measured the Fc $\gamma$ RI levels on leukocytes from patients with group $A$ hemolytic streptococcal (GABHS) pharyngitis. In this report, we show that monocytes and PMNs isolated from patients with GABHS pharyngitis have increased expression of Fc $\gamma$ RI, even though IFN- $\gamma$ is undetectable in the plasma.

\section{Methods}

Study population. Patients presenting to the walk-in clinic at Dartmouth-Hitchcock Medical Center with sore throat and three or more of the following criteria were eligible for the study: $(a)$ anterior neck adenopathy, $(b)$ tonsillar exudates, $(c)$ history of elevated temperature during the present illness, and $(d)$ absence of the new onset of cough. These criteria were chosen to increase the probability of selecting patients with true streptococcal pharyngitis (19). Healthy volunteer donors served as the control population. Patients presenting with sore throat who met the criteria for inclusion, but who had a negative throat culture for GABHS, were included in the study to serve as a second control population. A third study population included afebrile patients with a diagnosis of gram-negative urinary tract infection based on symptomatic dysurea, leukocyturia, and $\geq 100,000$ gram-negative bacteria per milliliter of urine. Patients with the above symptoms plus flank pain and fever were assigned the diagnosis of pyelonephritis.

Throat cultures were obtained from patients with pharyngitis by posterior pharyngeal swab. Specimens were plated on trypticase soy $/ 5 \%$ sheep blood agar plates and incubated under anaerobic conditions. Plates were examined at 24 and $48 \mathrm{~h}$ for beta hemolysis. Colonies of beta-hemolytic streptococci were further classified by latex agglutination grouping (Streptex, BBL Microbiology Systems, Baltimore MD)

Cell preparation. $20 \mathrm{ml}$ of venous blood was collected into $10-\mathrm{ml}$ vacutainer tubes containing sodium heparin (Becton Dickinson, 
Rutherford, NJ). Mononuclear cells were separated from PMN on Ficoll/Hypaque according to Boyum (20). PMNs were separated from RBC by dextran sedimentation (21). Nucleated cells were washed with RPMI 1640 and contaminating RBC were removed by osmotic lysis; osmolarity was restored with hypertonic PBS. Cells were washed again with RPMI 1640 and resuspended in RPMI/Hepes/0.2\% BSA. PMNs and mononuclear cells were recombined in a 1:4 ratio because we found this proportion to be optimal for analysis by flow cytometry.

$F c \gamma R$ assay. Fc $\gamma \mathrm{R}$ were examined by indirect immunofluoresence staining using purified $\mathrm{mAb}$ specific to each of the three known $\mathrm{Fc} \gamma \mathrm{R}$ (15). These are mAb 32 (Fc $\gamma \mathrm{RI}$; reference 12), mAb IV.3 (Fc $\gamma \mathrm{RII}$; reference 13) and mAb 3G8 (Fc $\gamma \mathrm{RIII}$; reference 14). $6.25 \times 10^{5}$ cells in $20 \mu \mathrm{l}$ were added to flat bottomed 96 -well plates on ice. Each well then received $20 \mu \mathrm{l}$ of human gamma globulin from a stock $(12 \mathrm{mg} / \mathrm{ml}$ Cohn Fraction V; Sigma Chemical Co., St. Louis, MO) to block binding of antibodies through their Fc region. $20 \mu \mathrm{l}$ of a $60 \mu \mathrm{g} / \mathrm{ml}$ stock of $\mathrm{mAb}$ to the $\mathrm{Fc} \gamma \mathrm{R}$ or a control $\mathrm{mAb}$ was then added to each of the wells. Plates were rotated at $4^{\circ} \mathrm{C}$ for $1 \mathrm{~h}$, cells were washed three times with $200 \mu$ l PBS containing $0.2 \%$ BSA, and then incubated $1 \mathrm{~h}$ with a saturating concentration of $\left(\mathrm{Fab}^{\prime}\right)_{2}$ FITC conjugated goat anti-mouse IgG (Caltag Laboratories, South San Francisco, CA). After another 1-h incubation, samples were washed $3 \times$ with PBS/BSA and resuspended in $\mathrm{PBS} / \mathrm{BSA} / 1 \%$ paraformaldehyde. mAb binding was evaluated by flow cytometry on an Ortho $50 \mathrm{H}$ flow cytometer using 300-mW, 488$\mathrm{nm}$ argon ion laser excitation, a 530-nm high pass filter, and a logarithmic amplifier. The relative number of $\mathrm{mAb}$ binding sites (reported as 2nd Ab sites/cell) was determined by comparing fluorescence of the cells to a curve generated using standardized fluorescence beads (Flow Cytometry Standards Corp., Research Triangle Park, NC) as described previously (15). Statistical analysis was by Student's $t$ test for unpaired values.

$I F N-\gamma$ assays. Plasma was obtained from the same heparinized tubes from which the leukocytes were isolated, made platelet-poor by centrifugation at $450 \mathrm{~g}$ for $30 \mathrm{~min}$, and frozen at $-70^{\circ} \mathrm{C}$ for up to $1 \mathrm{mo}$ before assay. Five plasma samples were also tested within $2 \mathrm{~h}$ of isolation. Samples were tested using a commercially available radioimmunoassay (Centecor, Inc., Malvern, PA) which is specific for bioactive IFN- $\gamma$, and by a bioassay which is based on increased expression of $\mathrm{Fc} \gamma \mathrm{RI}$ on U-937 cells that are cultured with the plasma and/or IFN- $\gamma$ (22). For the bioassay, $1 \times 10^{5}$ cells of the U-937 human promonocytic cell line were cultured at $37^{\circ} \mathrm{C}, 5 \% \mathrm{CO}_{2}$ for $18-24 \mathrm{~h}$ in 96 -well plates in a total volume of $200 \mu \mathrm{l}$ in RPMI 1640 medium (Hazleton, Denver, PA) supplemented with $20-80 \%$ plasma obtained from normal donors or from GABHS patients. After incubation, these U-937 cells were then analyzed by immunofluorescence flow cytometry for binding of mAb 32 .

\section{Results}

Streptococcal infection increases $F c \gamma R I$. Fig. $1 A$ summarizes the major finding of this study, that PMNs isolated on the day of initial evaluation from eight of nine patients with GABHS pharyngitis had significantly elevated levels of surface Fc $\gamma$ RI. PMNs from 12 healthy normal donors had $700 \pm 600$ (mean $\pm \mathrm{SD}$ ) $\mathrm{mAb} 32$ binding sites. 11 patients with pharyngitis and negative throat culture for GABHS had a mean of $2,100 \pm 1,600$ sites on their PMNs, a value significantly higher than for controls $(P<0.05)$. In contrast, PMNs from nine patients with documented GABHS pharyngitis had $11,600 \pm 7,500 \mathrm{mAb} 32$ binding sites on their surface. This was significantly higher than both the healthy donor group ( $P$ $<0.0005)$ and the GABHS-negative throat culture group ( $P$ $<0.0005)$. The GABHS-negative group included three patients (Nos. 2, 4, and 6, of Fig. 1, middle) who had cultures containing many $\beta$-hemolytic streptococci that were non group A. None of the PMNs from the 12 healthy donors expressed $>2,100$ sites and none of the GABHS-negative culture group expressed $>5,000$ sites. However, eight of nine patients
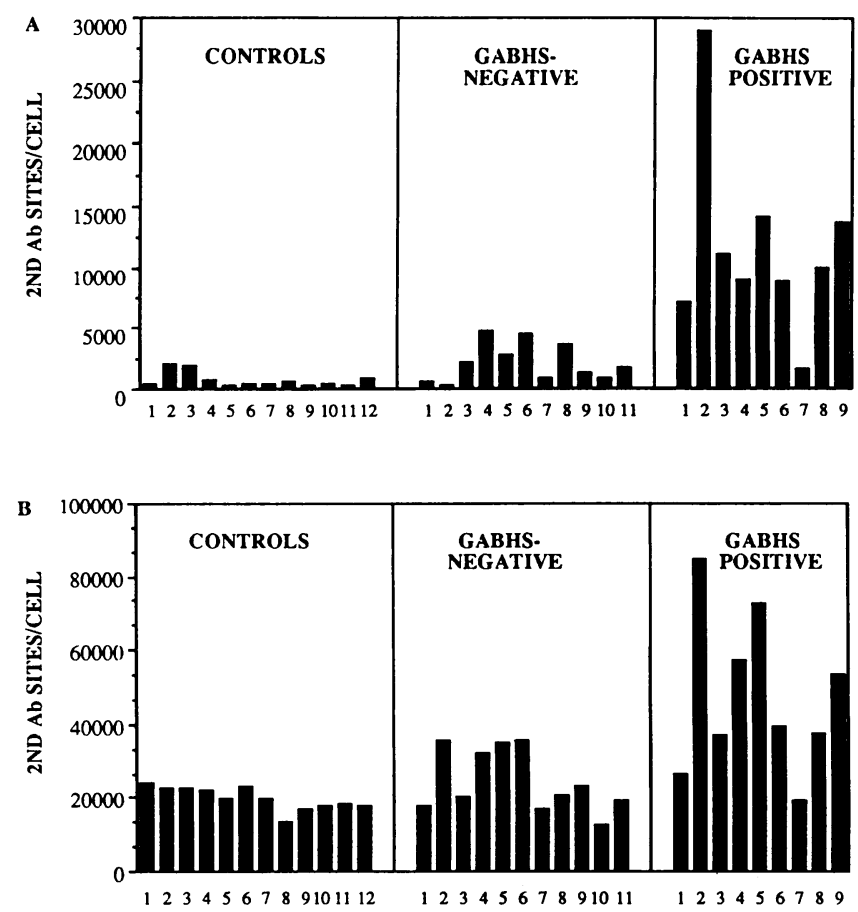

Figure 1. Fc $\gamma \mathrm{RI}$ levels are increased on PMNs $(A)$ and monocytes $(B)$ of patients with group A $\beta$-hemolytic streptococcal (GABHS) pharyngitis. Values are relative mAb 32 binding sites per cell calculated as described (15). Each bar is the value for a single donor.

with positive GABHS cultures had more than 6,000 sites per PMN. One patient (No. 7, Fig. 1, right) with a laboratory finding of "moderate" GABHS had control values for mAb 32 binding on both her PMNs and monocytes.

There was a similiar change in the expression of Fc $\gamma \mathrm{RI}$ on monocytes (Fig. 1 B), with control monocytes having $19,900 \pm 3,200 \mathrm{mAb} 32$ binding sites per cell and the positive GABHS monocytes having 47,500 $\pm 21,400 \mathrm{mAb} 32$ binding sites $(P<0.0005)$. The negative culture group had slightly elevated Fc $\gamma$ RI with a mean of $28,200 \pm 8,400$ sites. This was significantly different from both the normal controls $(P$ $<0.05)$ and from the positive GABHS group $(P<0.005)$. When cells from each GABHS positive donor were compared, there was a close correlation between elevated Fc $\gamma$ RI levels on PMNs (Fig. $1 A$, right) and on monocytes (Fig. $1 B$, right). During this study, one donor in the control group developed GABHS pharyngitis 6 mo after she was initially studied. For this donor, the number of mAb 32.2 binding sites per PMN increased from 1,900 before infection to 13,800 sites per cell during infection. Fc $\gamma$ RI per monocyte increased from 22,800 to 53,400 sites per cell.

Flow cytometric analysis enabled us to determine whether the increased expression of Fc $\gamma$ RI appeared on all cells or only on a subpopulation. Fig. 2 shows idealized histograms of the distribution that was found for all GABHS patients. In every case, the entire population of monocytes and PMNs displayed increased receptor expression.

To further determine the relationship between the disease process and $F c \gamma R I$ expression, we examined three additional patients for Fc $\gamma$ RI expression after they were identified by the laboratory as having a positive throat culture for GABHS. When these people were examined within $24 \mathrm{~h}$ after the specimen was obtained, they had elevated mAb32 binding sites on both monocytes and PMNs (Fig. 3). Fig. 3 includes the values 
A GRANULOCYTES
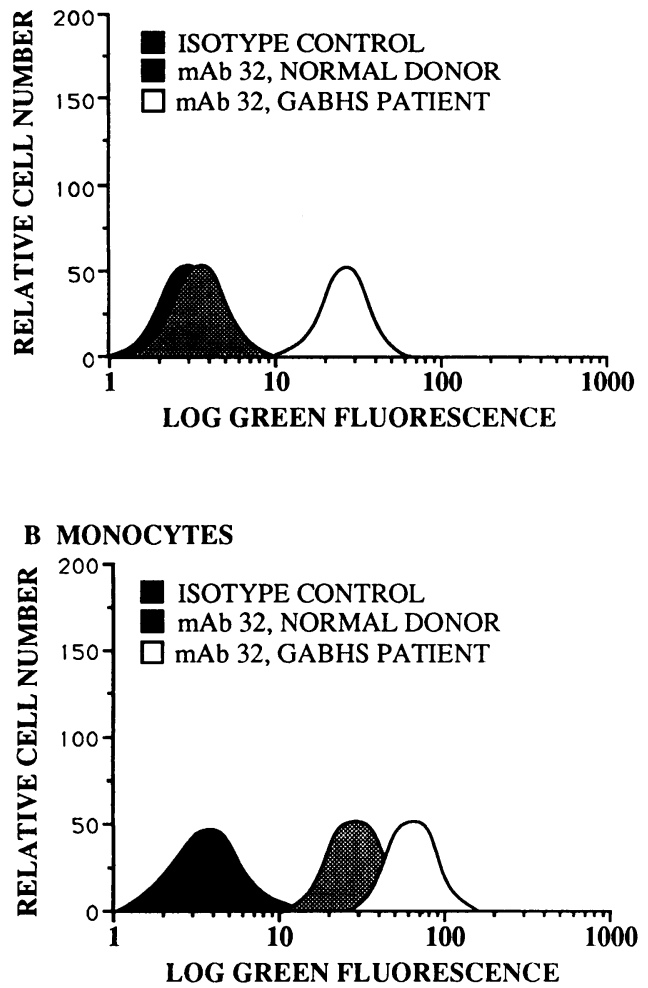

Figure 2. Immunofluorescence profiles for flow cytometric analysis of mAb 32 binding to granulocytes $(A)$ and monocytes $(B)$. Cells were isolated, stained, and analyzed as described in Methods.

for one donor (C.G.) who was followed sequentially for $3 \mathrm{~d}$. This donor had markedly elevated $\mathrm{Fc} \gamma \mathrm{RI}$ on both monocytes and PMN $24 \mathrm{~h}$ after the throat culture was obtained, but Fc $\gamma$ RI values dropped to normal after two additional days.

Streptococcal infection does not alter Fc $\gamma R I I$ or Fc $\gamma$ RIII. Two additional IgG Fc receptors, Fc $\gamma$ RII and Fc $\gamma$ RIII, are present on human myeloid cells (11). Although these $\mathrm{Fc} \gamma \mathrm{R}$ are not markedly affected by IFN- $\gamma$ in cell culture, we were interested to determine whether their expression was altered by streptococcal infection. We therefore used mAbs IV.3 and 3G8 to measure Fc $\gamma$ RII and Fc $\gamma$ RIII, respectively. Fig. 4 shows that the levels of binding of these $\mathrm{mAbs}$ were equivalent for all three groups. Thus, in contrast to $\mathrm{Fc} \gamma \mathrm{RI}$, the expression of $F c \gamma R I I$ and $F c \gamma$ RIII was unaffected by GABHS infection.

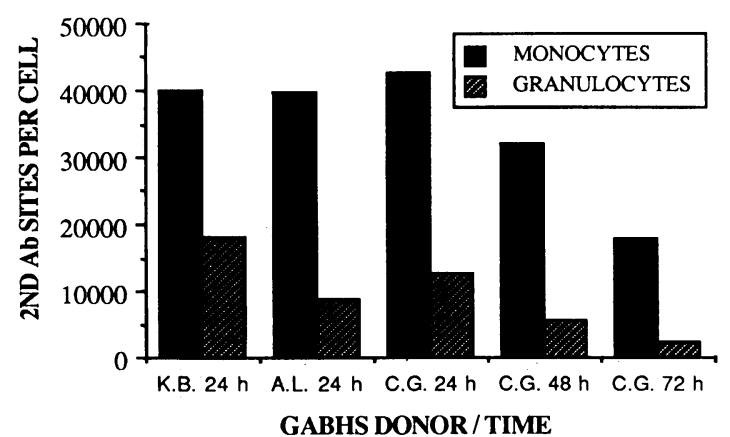

Figure 3. Fc $\gamma$ RI levels on monocytes and PMNs of three donors examined after the throat culture was shown to contain GABHS.

Times shown are hours after the initial clinical evaluation that subsequent blood samples were obtained.

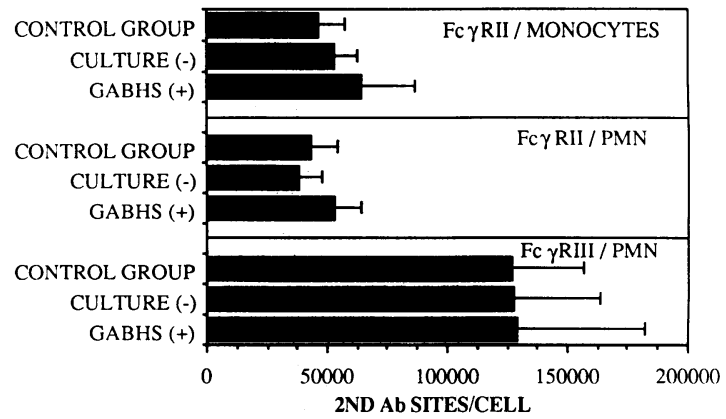

Figure 4. Fc $\gamma$ RII and Fc $\gamma$ RIII levels are unchanged on leukocytes of GABHS pharyngitis patients. Values are mean \pm SD mAb IV.3 (Fc $\gamma$ RII) and mAb 3G8 (Fc $\gamma$ RIII) sites per cell for the healthy control group $(n=12)$, the culture negative group $(n=11)$, and the GABHS pharyngitis positive group $(n=9)$.

Gram negative urinary tract infection does not alter $F c \gamma R I$ expression. 10 patients with documented urinary tract infections were found to not have increased binding of $\mathrm{mAb} 32$ to monocytes or PMN (Table I). Three patients with apparently uncomplicated pyelonephritis had a mean of 33,500 binding sites on their monocytes and 3,400 sites on their PMN, levels similar to pharyngitis patients who were GABHS negative. Two additional pyelonephritis patients had elevated Fc $\gamma \mathrm{RI}$ on their PMNs. These patients, in addition to pyelonephritis, also had either $E$. coli septicemia or pneumonia of unknown etiology (Table I).

IFN- $\gamma$ is undetectable in patient's plasma. IFN- $\gamma$ is a potent inducer of $\mathrm{Fc} \gamma \mathrm{RI}$ expression by both monocytes and PMNs $(9,10,15)$ and its production is induced by streptococcal antigens $(17,18)$. We therefore examined plasma samples, obtained at the same time that elevated numbers of Fc $\gamma \mathrm{RI}$ were detected on leukocytes, for the presence of IFN- $\gamma$. Seven plasma samples were obtained and frozen at $-70^{\circ} \mathrm{C}$, then tested using an IFN- $\gamma$-specific RIA (Centocor, Inc., Malvern, PA). All samples had undetectable IFN- $\gamma(<1 \mathrm{U} / \mathrm{ml})$.

We next obtained blood from three donors as soon as possible after their throat cultures were found to contain GABHS, examined the cells for $\mathrm{F} c \gamma \mathrm{RI}$ expression, and tested the plasma within $2 \mathrm{~h}$ of isolation for IFN- $\gamma$. This test for IFN- $\gamma$ included both the RIA and a bioassay (22) which detects increased expression of $\mathrm{Fc} \gamma \mathrm{RI}$ on the U-937 cell line. Fig. 5 shows the result for plasma samples obtained from donors K.B. and A.L.; leukocyte Fc $\gamma$ RI levels for the same blood samples are shown to be elevated in Fig. 3. Neither plasma from the normal donor (CON) nor from the GABHS patients (K.B. and A.L.) caused a significant increase in $\mathrm{mAb} 32$ binding to

Table I. MAb 32 Binding in Gram-negative Infections

\begin{tabular}{|c|c|c|}
\hline \multirow[b]{2}{*}{ Diagnosis } & \multicolumn{2}{|c|}{ Relative mAb 32 sites per cell* } \\
\hline & Monocytes & PMN \\
\hline Urinary tract infection $(n=10)$ & $18000 \pm 5100$ & $1580 \pm 1200$ \\
\hline Pyelonephritis $(n=3)$ & $33500 \pm 3000$ & $3400 \pm 2500$ \\
\hline $\begin{array}{l}\text { Pyelonephritis }+E \text {. coli septicemia } \\
\quad(n=1)\end{array}$ & 4300 & 6200 \\
\hline $\begin{array}{l}\text { Pyelonephritis + pneumonia } \\
\quad(n=1)\end{array}$ & 31900 & 10660 \\
\hline
\end{tabular}

* Relative mAb 32 sites per cell determined by immunofluorescence plus flow cytometry as described in reference 15 . 
TREATMENT

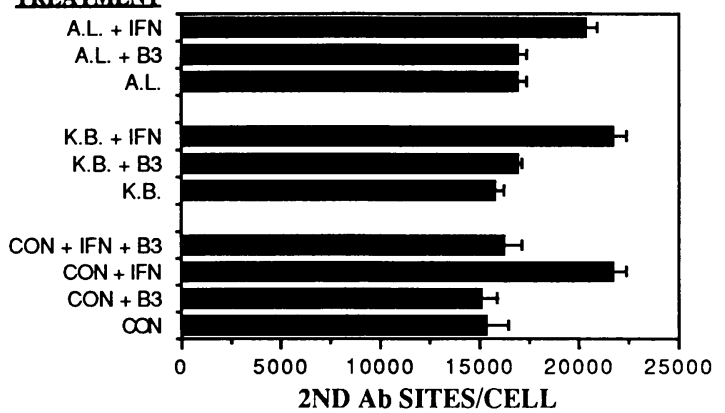

Figure 5. Bioassay of plasma for IFN- $\gamma$. Plasma obtained from two patients (A.L. and K.B.) or from a control donor (CON) was tested for its ability to induce increased expression of $\mathrm{Fc} \gamma \mathrm{RI}$ on U937 cells as described in Methods. Values are relative mAb 32 binding sites per U937 cell after culture with plasma (CON, K.B., or A.L.), plasma plus mAb B3 (which neutralizes IFN- $\gamma$ ), or plasma plus 1 $\mathrm{U} / \mathrm{ml}$ IFN- $\gamma$.

U-937 cells that were cultured with $40 \%$ plasma for $18 \mathrm{~h}$. However, each plasma sample, when supplemented with 1 $\mathrm{U} / \mathrm{ml}$ rIFN- $\gamma$, caused a $40 \%$ increase in Fc $\gamma$ RI expression, which was blocked by the IFN- $\gamma$ neutralizing monoclonal antibody B3 (23). This experiment demonstrates that the bioassay detects as little as $0.4 \mathrm{U} / \mathrm{ml}$ IFN- $\gamma$, and that the plasma from GABHS patients who have elevated Fc $\gamma$ RI levels on their leukocytes contains $<1 \mathrm{U} / \mathrm{ml}$ IFN- $\gamma$. Additional assay points (not shown) included 60 and $80 \%$ plasma, and gave similar results, leading us to conclude that the plasma samples tested contained $<0.5 \mathrm{U} / \mathrm{ml}$ IFN- $\gamma$.

\section{Discussion}

Because Fc receptors mediate the ingestion of opsonized bacteria, a mechanism to increase $F c$ receptor expression during infection would seem to be physiologically important. In previous reports, we and others showed that IFN- $\gamma$ causes a dramatic increase in expression of Fc $\gamma \mathrm{RI}$ on monocytes, the monocyte like cell line U-937, and PMNs, both in vitro and in vivo $(9,10,15,16)$. Because streptococcal antigens are potent inducers of IFN- $\gamma(18,19)$, we postulated that IFN- $\gamma$ would be produced endogenously in vivo in patients with streptococcal infections. With the studies presented in this paper, we have in fact demonstrated that Fc $\gamma$ RI expression is induced on PMNs and augmented on monocytes isolated from patients with GABHS pharyngitis. However, we were unable to detect IFN- $\gamma$ in the plasma of these patients, even when their Fc $\gamma$ RI levels were very high, and the plasma was tested immediately upon isolation. In other experiments (not shown), we determined that the activity of rIFN- $\gamma$ was not reduced by adding it to GABHS plasma or by storage at $-70^{\circ} \mathrm{C}$. Because both our bioassay and the RIA had sensitivities in the range of $1 \mathrm{U} / \mathrm{ml}$ IFN- $\gamma$, we conclude that circulating levels of IFN- $\gamma$ are below this level even in patients, such as K.B. (Figs. 3 and 5), who were febrile and had greatly elevated expression of Fc $\gamma$ RI when the blood sample was obtained.

The absence of detectable IFN- $\gamma$ in the circulation suggests: $(a)$ that elevated Fc $\gamma$ RI may be mediated by locally high concentrations of IFN- $\gamma,(b)$ that the short circulating half-life of IFN- $\gamma$ may result in undetectable levels even though levels were initially high; or $(c)$ that other cytokines or hormones may contribute to increased Fc $\gamma \mathrm{RI}$ in addition to (or instead of) IFN- $\gamma$. The first possibility seems unlikely since the entire population of monocytes and PMNs, rather than a subpopu- lation, had elevated Fc $\gamma$ RI (Fig. 2). Thus, streptococcal infection results in systemic activation of $F c \gamma R I$ expression in all circulating monocytes and PMNs. The second possibility is plausible since the serum half-life of rIFN- $\gamma$ has been estimated to be between 0.5 and $3 \mathrm{~h}$ (24-26). Moreover, Chatenoud et al. (27) reported a rapid induction and rapid decline in serum IFN- $\gamma$ levels following clinical administration of $\mathrm{mAb}$ OKT3 for prevention of acute allograft rejection. Thus, IFN- $\gamma$ levels could transiently be as high as $1,000 \mathrm{U} / \mathrm{ml}$ and then fall to undetectable levels $24 \mathrm{~h}$ later. To further test the plausibility of this hypothesis, we exposed two groups of PMN to $50 \mathrm{U} / \mathrm{ml}$ IFN- $\gamma$ for $3 \mathrm{~h}$, washed out the IFN- $\gamma$ from one group, and then cultured the cells for an additional $18 \mathrm{~h}$. The two groups had similar increases in $\mathrm{Fc} \gamma \mathrm{RI}$, indicating that transient exposure to IFN- $\gamma$ is sufficient to induce increased Fc $\gamma$ RI expression 18 $h$ later on human PMNs. It will be interesting to determine whether OKT3 therapy stimulates a similar increase in Fc $\gamma$ RI expression.

To test the possibility that other cytokines might influence the expression of Fc $\gamma$ RI, we cultured PMNs with recombinant IFN- $\alpha$, IFN- $\beta$, interleukin 2 , interleukin 3 , tumor necrosis factor, granulocyte-colony stimulating factor (G-CSF), and granulocyte/macrophage-colony stimulating factor, both alone and in combination with $50 \mathrm{U} / \mathrm{ml}$ IFN- $\gamma$. IFN- $\gamma$ caused a 10- to 20-fold increase in Fc $\gamma \mathrm{RI}$ as previously reported (15), and G-CSF caused a two- to three-fold increase that was additive with that of IFN- $\gamma$ (manuscript in preparation). None of the other cytokines enhanced Fc $\gamma$ RI expression. Further study will be required to determine whether a combination of immune cytokines and/or other hormones can increase Fc $\gamma$ RI expression sufficiently to account for the effects we have observed in GABHS patients.

Patients who met the criteria for inclusion in this study but had negative throat cultures most likely represented cases of viral infection. It is interesting that Fc $\gamma \mathrm{RI}$ expression was increased to a much lesser extent on PMNs and monocytes in these patients. PMNs from all donors in the control and GABHS culture-negative groups had $<5,000$ mAb 32 sites per cell, while PMNs from 11 of 12 GABHS culture-positive donors had $>6,000$ sites per cell. The one sample that did not show a rise in Fc $\gamma$ RI may have been a false positive case in which the patient was colonized but not infected with GABHS. It is also possible that this patient was indeed infected with GABHS, but did not respond to infection by increased Fc $\gamma$ RI expression. It will be interesting to determine whether there is a relationship between protracted streptococcal infections and a failure to exhibit increased Fc $\gamma$ RI expression. Further study will be required to determine whether a combination of immune cytokines and/or other hormones can increase Fc $\gamma$ RI expression sufficiently to account for the effect we have observed in GABHS patients.

Although streptococcal pharyngitis represents a relatively minor bacterial infection, we have demonstrated that this degree of infection is able to systematically activate the immune system, as evidenced by increased Fc $\gamma$ RI expression on peripheral blood myeloid cells. It seems likely, therefore, that patients with systemic infectious illness will also have elevated levels of Fc $\gamma$ RI. Consistent with this possibility, PMNs isolated from patients seriously ill with bacterial and fungal sepsis have been shown to be activated, as demonstrated by an increased capacity for maximal superoxide production (28). Fc $\gamma R$ expression was not evaluated in these patients. However, Simms et al. (29) used radiolabeled mAb 32 to demonstrate that two patients with acute bacterial infections had in- 
creased Fc $\gamma$ RI expression on their PMNs. The same authors found Fc $\gamma$ RII and Fc $\gamma$ RIII expression to be similar on patient and control PMNs. It can thus be concluded from our study and that of Simms et al. that $\mathrm{Fc} \gamma \mathrm{RI}$ is selectively increased in at least some bacterial infections. Moreover, our data show that gram-negative urinary tract infections do not activate the mechanisms leading to increased expression of Fc $\gamma$ RI. Also, although our sample size is small, it is apparent that $E$. coli pyelonephritis causes a lower level of activation than does GABHS infection.

In summary, we find increased $\mathrm{Fc} \gamma \mathrm{RI}$ expression on the entire circulating pool of both PMNs and monocytes isolated from patients with GABHS pharyngitis. This increase might result from a transiently high level of production of IFN- $\gamma$ and G-CSF, but probably reflects the interactive effects of several as yet to be identified hormones and cytokines. Further studies will be required to determine the types of infectious illnesses that are associated with increased expression of $\mathrm{Fc} \gamma \mathrm{RI}$.

\section{Acknowledgments}

We appreciate the assistance of Rosemary Bruce, R.N., Richard Delaney, PA-C, and Nick Jacobs, Ph.D. in obtaining specimens. We thank Milton Brown, Veronica Guyre, and Gary Ward for their help with flow cytometric analysis, and Sharon Fanger for her unique editorial assistance. MAbs IV.3, 3G8, and B3 were kindly provided by Clark Anderson, Jay Unkeless, and Junming Le, respectively. Interferons were generous gifts of Genentech, Inc. and Hoffman LaRoche, Inc. Other cytokines were kindly provided by Immunex, Inc.

This work was supported by National Institutes of Health grants DK 33100, CA 17323, AI 19053, and CA 44794. The cytofluorograph was the generous gift of the Fannie Rippel Foundation, and is partially supported by the core grant of the Norris Cotton Cancer Center (CA23108).

\section{References}

1. Suzuki, Y., M. A. Orellana, R. D. Schreiber, and J. S. Remington. 1988. Interferon- $\gamma$ : the major mediator of resistance against Toxoplasma gondii. Science (Wash. DC). 240:516-518.

2. Buchmeier, N. A., and R. D. Schreiber. 1985. Requirement of endogenous interferon- $\gamma$ production for the resolution of Listeria monocytogenes infection. Proc. Natl. Acad. Sci. USA. 82:7404-7408.

3. Murray, H. W., B. Y. Rubin, and C. D. Rothermel. 1983. Killing of intracellular Leishmania donovani by human mononuclear phagocytes. Evidence that interferon- $\gamma$ is the activating lymphokine. J. Clin. Invest. 72:1506-1510.

4. Li, H., T. R. Jerrells, G. L. Spitalny, and D. H. Walker. 1987. Gamma interferon as a crucial host defense against Rickettsia conorii in vivo. Infect. Immun. 55:1252-1255.

5. Murray, H. W., G. L. Spitalny, and C. F. Nathan. 1985. Activation of mouse peritoneal macrophages in vitro and in vivo by interferon- $\gamma$. J. Immunol. 134:1619-1622.

6. Nathan, C. F., C. R. Horowitz, J. de la Horpe, S. Vadhan-Raj, H. F. Sherwin, and S. E. Krown. 1985. Administration of recombinant interferon- $\gamma$ to cancer patients enhances monocyte secretion of hydrogen peroxide. Proc. Natl. Acad. Sci. USA. 82:8686-8690.

7. Varesio, L., E. Blasi, G. B. Thurman, J. E. Talmadge, R. H. Wiltrout, and R. B. Herberman. 1984. Potent activation of mouse macrophages by recombinant IFN- $\gamma$. Cancer Res. 44:4465-4469.

8. Nathan, C. F., T. J. Prendergast, M. E. Wiebe, E. R. Stanley, E. Platzer, H. G. Remold, K. Welte, B. Y. Rubin, and H. W. Murray. 1984. Activation of human macrophages: comparison of other cytokines with interferon- $\gamma . J$. Exp. Med. 160:600-605.

9. Guyre, P. M., P. M. Morganelli, and R. Miller. 1983. Recombinant immune interferon increases immunoglobulin $\mathrm{G} F \mathrm{~F}$ receptors on cultured mononuclear phagocytes. J. Clin. Invest. 72:393-397.
10. Perussia, B., E. T. Dayton, V. F. Lazarus, and G. Trinchieri. 1983. Immune interferon induces the receptor for monomeric IgG1 on human monocytic and myeloid cells. J. Exp. Med. 158:1092-1113.

11. Unkeless, J. C. 1989. Function and heterogeneity of human Fc receptors for immunoglobulin G. J. Clin. Invest. 83:355-361.

12. Anderson, C. L., P. M. Guyre, J. C. Whitin, D. H. Ryan, R. J. Looney, and M. W. Fanger. 1986. Monoclonal antibodies to the Fc receptors for IgG on human mononuclear phagocytes: antibody characterization and induction of superoxide production in a monocyte cell line. J. Biol. Chem. 261:12856-12864.

13. Looney, R. J., G. N. Abraham, and C. L. Anderson. 1986. Human monocytes and U937 cells bear two distinct Fc receptors for IgG. J. Immunol. 136:1641-1647.

14. Fleit, H. B., S. D. Wright, and J. W. Unkeless. 1982. Human neutrophil $\mathrm{Fc} \gamma$ receptor distribution and structure. Proc. Natl. Acad. Sci. USA. 79:3275-3279.

15. Petroni, K. C., L. Shen, and P. M. Guyre. 1988. Modulation of human polymorphonuclear leukocyte IgG Fc receptors and Fc receptor-mediated functions by IFN- $\gamma$ and glucocorticoids. J. Immunol. 140:3467-3472.

16. Maluish, A. E., W. J. Urba, D. L. Longo, W. R. Overton, D. Coggin, E. R. Crisp, R. Williams, S. A. Sherwin, K. Gordon, and R. G. Steis. 1988. The determination of an immunologically active dose of interferon gamma in patients with melanoma. J. Clin. Oncol. 6:434445 .

17. Matsubara, S., F. Suzuki, and N. Ishida. 1979. Induction of immune interferon in mice treated with a bacterial immunopotentiator, OK 432. Cancer Immunol. Immunother. 6:41-46.

18. Kimura, S., T. Inoue, T. Yamashita, Y. Midorikawa, S. Arai, and F. Sendo. 1987. Production of factor(s) that render polymorphonuclear leukocytes cytotoxic from spleen cells stimulated with streptococcal preparation, OK-432. Cancer Res. 47:6204-6209.

19. Centor, R. M., J. M. Witherspoon, H. P. Dalton, C. E. Brody, and K. Link. 1981. The diagnosis of strep throat in the emergency room. Med. Decis. Making. 1:239-246.

20. Boyum, A. 1968. Isolation of mononuclear cells and granulocytes from human blood. J. Lab. Clin. Invest. 21(Suppl. 97): 77.

21. Graziano, R. F., and M. W. Fanger. 1987. Fc $\gamma$ RI and Fc $\gamma$ RII on monocytes and granulocytes are cytotoxic trigger molecules for tumor cells. J. Immunol. 139:3536-3541.

22. Guyre, P. M., P. M. Morganelli, F. Fillian, R. Miller, and J. E. Bodwell. 1984. Virus-free bioassay of human immune interferon by flow cytometric analysis of Fc receptor modulation. Fed. Proc. 43:1830.

23. Le, J., and J. Vilcek. 1984. Lymphokine-mediated activation of human monocytes: neutralization by monoclonal antibody to interferon- $\gamma$. Cell Immunol. 85:278-283.

24. van der Burg, M., M. Edelstein, L. Gerlis, C.-M. Liang, M. Hirschi, and A. Dawson. 1985. Recombinant interferon- $\gamma$ (immuneron): results of a phase I trial in patients with cancer. J. Biol. Resp. Modifiers. 4:264-272.

25. Foon, K. A., S. A. Sherwin, P. G. Abrams, H. C. Stevenson, P. Holmes, A. E. Maluish, R. K. Oldham, and R. B. Herberman. 1985. A phase I trial of recombinant gamma interferon in patients with cancer. Cancer Immunol. Immunother. 20:193-197.

26. Vadhan-Raj, S., A. Al-Katib, R. Bhalla, L. Pelus, C. F. Nathan, S. A. Sherwin, H. F. Oettgen, and S. E. Krown. 1986. Phase I trial of recombinant interferon gamma in cancer patients. J. Clin. Oncol. 4:137-146.

27. Chatenoud, L., C. Ferran, C. Legendre, P. Franchimont, A. Reuter, H. Kreis, and J.-F. Bach. 1988. Clinical use of OKT3: the role of cytokine release and xenosensitization. J. Autoimmunity. 1:631640 .

28. Bass, D. A., P. Olbrantz, P. Szejda, M. C. Seeds, and C. E. McCall. 1986. Subpopulations of neutrophils with oxidative product formation in blood of patients with infection. J. Immunol. 136:860 866.

29. Simms, H. H., M. M. Frank, T. C. Quinn, S. Holland, and T. Gaither. 1989. Studies on phagocytosis in patients with acute bacterial infections. J. Clin. Invest. 83:252-260. 